\title{
Kulak Burun Boğaz Uzmanlık Eğitiminde 360 Değerlendirme
}

\section{0-degree Evaluation in Otorhinolaryngology Residency Training}

Cüneyt Orhan Kara (ORCID ID: 0000-0003-2219-4283)

Erdem Mengi (ORCID ID: 0000-0001-8813-2443)

Pamukkale Üniversitesi Tıp Fakültesi KBB AD, Denizli

İletişim Adresi: Prof Dr Cüneyt Orhan Kara

Pamukkale Üniversitesi Tıp Fakültesi KBB AD, Denizli

cokara@yahoo.com

Anahtar Sözcükler:

360 derece değerlendirme,

çok kaynaklı geri

bildirim, iş başında ölçme değerlendirme, uzmanlık eğitimi

Keywords:

360-degree evaluation, multisource feedback, workplace-based assessment, residency training

Gönderilme Tarihi

Submitted:20.02.2019

Kabul Tarihi

Accepted: 26.05.2019
ÖZET:

Amaç; Kulak Burun Boğaz (KBB) Uzmanlık eğitiminde uzmanlık öğrencilerinin değerlendirilmesinde $360^{\circ}$ değerlendirme yönteminin kullanılabilirliği, uygulamadaki zorluklar ve değerlendiricilerin tepkileri araştırılmıştır.

Yöntem; İlk aşamada $6 \mathrm{KBB}$ uzmanlık öğrencisi için standart $360^{\circ}$ değerlendirme yapıldı. Değerlendirici olarak yedi farklı grup anket doldurmuştur. Ayrıca her uzmanlık öğrencisi hem kendisi ve hem de arkadaşları için değerlendirme yaptılar. Değerlendirme sonucunda düşük puan alınan başlıklar öğretim üyeleri ve uzmanlık öğrencisi ile yüz yüze görüşülmüştür. Araştırmanın ikinci aşamasında uzmanlık öğrencileri ve öğretim üyelerinden, $360^{\circ}$ değerlendirme sürecine ilişkin yazılı ve sözlü geri bildirimler alınmıştır. Test güvenilirliği ve öğrenciler arası korelasyon istatistiksel olarak hesaplanmıştır. Nitel değerlendirmede ise geri bildirimler ve araştırmacıların aldığı yazılı notlar, ilgili başlıklar altında toplanarak değerlendirilmiştir.

Bulgular; Toplamda 205 anket doldurulmuştur. Testin alt başliklarında hesaplanan Cronbach alfa değerleri sonucunda anketlerin güvenilir olduğu görülmüştür. Artan kıdem yılı ile toplanan puanlar arasında pozitif yönde istatistiksel olarak anlamlı ve kuvvetli korelasyon saptanmıştır. Uzmanlık öğrencileri ve değerlendiricilerin $360^{\circ}$ değerlendirmeyi olumlu karşıladıkları gözlenmiştir. Eğiticiler sonuçların davranış değişikliğine yol açacağına inanırken, uzmanlık öğrencilerinin de çoğunluğu bu düşünceyi paylaşmıştır. Negatif sonuçların öğrencilere bildirilmesinde ve iyileştirme planları yapılırken zorluklarla karşılaşılmıştır.

Makale Künye Bilgisi: Kulak Burun Boğaz Uzmanlık Ĕ̆itiminde $360^{\circ}$ Değerlendirme. Tıp Ĕ̆itimi Dünyast. 2019;18(55): 80-91 
Ayrıca araştırmada veri toplama ve değerlendirme sürecinin yoğun emek gerektirdiği gözlenmiştir.

Sonuç; $360^{\circ} \mathrm{d}$ yöntemi KBB uzmanlık öğrencileri, eğiticiler ve değerlendiriciler tarafindan ilgiyle karşılanmıştır. Araştırma da $360^{\circ} \mathrm{d}$ tüm aşamalarının çok yoğun emek gerektirdiği görülmüştür. Sonuçların uzmanlık öğrencilerine bildirilmesinde ve danışmanlık süreçlerinde zorluklarla karşılaşılmıştır. Bu nedenlerle, rutin uygulamaya geçmeden önce iyi planlanmış bir hazırlık yapılması tavsiye edilir.

\section{ABSTRACT:}

Background: To investigate the utiliy of the 360-degree evaluation $\left(360^{\circ}\right)$ in Otorhinolaryngology residency training program, barriers in implementation and reactions of the evaluators.

Methods: Initially, standard 360-degree evaluation was implemented among 6 residents in otorhinolaryngology. Seven different evaluator groups completed the assessment forms. In addition, each resident evaluated both themselves and their peers. After the assessment, headings with low scores were evaluated face to face with the educators and the resident. In the second phase, residents and educators were asked for feedback on the process of 360-degree evaluation. For the quantitative assessment, test reliability and correlation between the residents were examined. For the qualitative assessment, the feedback of the participants and notes of the researchers were investigated.

Results: A total of 205 forms were completed. The evaluation tool was found reliable according to the Cronbach's Alpha values in the sub-headings. A statistically significant positive correlation was found between the years of seniority and the scores. It was observed that the residents and evaluators reviewed the 360-degree evaluation favourably. The educators believed the results would lead to a change in behavior and the majority of the residents agreed with the statement. On the other hand, it was observed that the process of data collection and assessment took a long time.

Conclusions: The 360-degree evaluation was welcomed with interest by otorhinolaryngology trainees, trainers and evaluators. However, it was seen that all stages of the 360-degree evaluation require very intensive labor. Difficulties were encountered in reporting the results to the students and in the counseling process. For these reasons, it is recommended to have a well-planned preparation before routine practice.

\section{GíRIŞ}

Uzmanlık eğitiminde zaman temelli eğitimden, yeterlik temelli eğitime geçilmektedir. Ülkemizde de Tipta Uzmanlık Kurulu (TUK) tarafından bu konuda çalışmalar yapılmaktadır. Türk Kulak Burun Boğaz Baş ve Boyun Cerrahisi (KBB) Uzmanlık eğitiminde de yeterlik temelli eğitim için çekirdek program yayınlanmıştır (1). Takip eden süreçte KBB uzmanlık eğitimiyle ilgili çekirdek eğitim programı geliştirilmiş, yeterlik kurulu eğitim komisyonu tarafindan da KBB Uzmanlık karnesi oluşturulmuştur $(2,3)$.

TUK, KBB Uzmanlık çekirdek eğitim programında yedi temel yeterlik alanı belirlemiştir (1, 2). Bu alanlar hizmet sunucusu, öğrenen ve öğreten, iletişim kuran, ekip üyesi, yönetici, değer ve sorumluluk sahibi ve sağlık koruyucusu başlıkları altında toplanmaktadır. KBB uzmanlık eğitimi sürecinde her öğrencinin bu alanlarda yeterli olduğunun gösterilmesi gerekmektedir. Uzmanlık eğitiminde, asistanların KBB alanındaki bilgi ve 
becerilerini değerlendirmek, KBB eğiticilerinin uyguladıkları ve uzak olmadıkları bir alandır. Diğer yandan temel yeterlikler olarak tarif edilen ve yukarıda bahsi geçen başlıklar, geleneksel uzmanlık eğitiminde yapılandırılmış bir eğitim süreci içerisinde yer almamakta ve bu konularda yapılandırılmış ölçme değerlendirme araçları kullanılmamaktadır. Bu alanlar daha çok usta çırak ilişsisi içinde öğrenilmektedir. Dolayısıyla bu başlıklar hem uzmanlık öğrencileri, hem eğiticiler için yeni alanlardır.

“360 değerlendirme” $\left(360^{\circ} \mathrm{d}\right)$, diğer adıyla "çok kaynaklı geri bildirim" iletişim becerileri, profesyonellik, liderlik gibi alanlarda uzmanlık öğrencilerinin yeterliklerinin değerlendirilmesi için geliştirilmiş, geçerlik ve güvenirlik gibi psikometrik çalışmaları yapılmış bir ölçme değerlendirme aracıdır $(4,5,6)$. Bu yöntemde uzmanlık öğrencileri sadece eğiticiler tarafından değil, eğitim ortamında birlikte çalıştığ1 tüm kişiler tarafından değerlendirilmektedir. $360^{\circ} \mathrm{d}$ tıp eğitiminde mezuniyet öncesi eğitimden, aktif profesyonel hayata kadar, yani sahada hizmet veren uzmanların tutumlarının değerlendirilmesine kadar oldukça farklı amaçlarla kullanılabilmektedir. $\mathrm{Bu}$ araştırmada ise cerrahi bir branş örneği olarak KBB uzmanlık öğrencilerinin eğitimindeki uygulamadaki kullanımı incelenmiştir. $360^{\circ} \mathrm{d}$ yönteminin ülkemizde KBB Uzmanlık eğitiminde taraflar tarafından nasıl karşılanacağı ve uygulama sürecindeki karşılaşılacak olası zorluklar bilinmemektedir. Alan yazın incelendiğinde $360^{\circ} \mathrm{d}$ için ülkemizde sadece iki uygulamaya ait deneyimlerin paylaşıldığı görülmektedir $(5,6)$. KBB uzmanlık eğitimi alanında ise bu yöntemle ilgili bir araştırma raporuna rastlanmamıştır. $\mathrm{Bu}$ çalışmada KBB Uzmanlık eğitiminde $360^{\circ} \mathrm{d}$ yöntemi için uzmanlık öğrencilerinin, öğretim üyelerinin ve diğer değerlendiricilerin tepkileri ve yöntemin uygulanabilirliği araştırılmıştır.

\section{Gereç ve Yöntem}

Araştırma iki bölümden oluşmaktadır. İlk bölüm KBB Uzmanlık öğrencileri için $360^{\circ}$ değerlendirme yapıldığ 1 aşamadır. $360^{\circ}$ değerlendirme sürecine Pamukkale Üniversitesi Tıp Fakültesi KBB kliniğinde çalışmakta olan 6 uzmanlık öğrencisi katılmıştır. Her uzmanlık öğrencisinden bilgilendirilmiş yazılı onam alınmıştır. Değerlendirici grubu olarak uzmanlık öğrencilerinin birlikte çalıştı̆̆ 1 , en çok sayıda kişiye ulaşılması planlanmıştır. Veri toplama sürecinde her değerlendiriciye araştırmanın amacı açıklanmış ve sonuçların uzmanlık öğrencilerine anonim olarak sunulacağ1 belirtilmiştir. Veri toplamak için Oktay ve ark. Accreditation Council for Graduate Medical Education'ın belirlediği yeterlik alanlarına yönelik geliştirdiği anketlerden yararlanılmıştır (5). $\mathrm{Bu}$ anket profesyonalizm (p), iletişim becerisi (i), hasta bakımı (hb) ve sistem temelli uygulama(stu) alt anketlerden oluşmaktadır. Her değerlendirici gruba uygun alt anketler seçilerek uygulanmıştır. Hangi anketlerin hangi gruplara sorulduğu tablo 1 'de görülmektedir. Hastalara ve tıp fakültesi öğrencilerine ise daha kolay doldurabilecekleri anketler geliştirilmiştir. Her anket sonunda da değerlendiricinin konuyla ilgili yazmak istediklerini bildirebilmesi için yer mevcuttur.

Verilerin toplanmasını ve değerlendirilmesini takiben her öğrenci için bir rapor hazırlanmıştır. Değerlendiricilerden elde edilen sonuçlar raporda anonim olarak yer almıştır. Anketlerin sonunda yer alan, serbest geribildirimlere ise her uzmanlık öğrencisine verilen raporda orjinalinde yazıldı̆̆ gibi yer verilmiştir. Her öğrenciye kişisel olarak hazırlanan bu raporlar kısa açıklayıcı bir metinden oluşan bir kapak sayfası ile kapalı zarflar içinde bireysel olarak sunulmuştur. Her öğrenci sadece kendisine ait sonuçları görebilmiştir. İki gün sonrasında 
anabilim dalı başkanı ve diğer öğretim üyelerinin katılımıyla bir toplantı yapılıp, $360^{\circ} \mathrm{d}$ 'lerden düşük puan alınan başlıklar, her uzmanlık öğrencisiyle bir kez de yüz yüze karşılıklı olarak konuşulmuş, gelişim planları yapılmıştır. $\mathrm{Bu}$ şekilde eğitim sürecine ait planladığımız rutin $360^{\circ} \mathrm{d}$ süreci tamamlanmıştır $(5,6)$.

Araştırmanın ikinci bölümünde ise $360^{\circ} \mathrm{d}$ yöntemi hakkında geri bildirim aşamasına geçilmiştir. Öncelikle uzmanlık öğrencilerinin $360^{\circ} \mathrm{d}$ konusundaki fikirlerini 8 sorudan oluşan bir formla (Tablo 2) yazılı olarak bildirmeleri istenmiştir. Takiben süreç ve sonuçlarla ilgili toplantılar yapılarak önce uzmanlık öğrencilerinin, sonrasında öğretim üyelerinin aynı 8 soruya cevapları sözlü geribildirim şeklinde de toplanmıştır. Her iki toplantıdaki sözlü geri bildirimler toplantı sırasında araştırmacılardan tarafından kısa notlar alınarak kayıt edilmiş, toplantı sonunda araştırmacılar tarafindan ortak fikir birliği oluşturacak şekilde özetlenmiştir. Bu kayıtlar araştırma sonunda iki araştırmacı tarafından tekrar gözden geçirilerek önemli noktalar nitel değerlendirme için kaynak olarak kullanılmıştır.

Verilerin İstatistiksel Analizi

Araştırmada elde edilen veriler Statistical Package for the Social Sciences 22.0 program (IBM Corp.; Armonk, NY, ABD) paket programıyla analiz edilmiştir. Anketlerin güvenirliği için Cronbachalfa katsayısı hesaplanarak iç tutarlılık bakılmıştır. KBB Uzmanlık öğrencilerinin aldıkları puanlar ve kıdem yılı arasındaki ilişkilerin incelenmesinde Pearson korelasyon analizi kullanılmıştır. Tüm analizlerde $\mathrm{p}<0,05$ istatistiksel olarak anlamlı kabul edilmiştir. Araştırma için Pamukkale Üniversitesi girişimsel olmayan klinik araştırmalar etik kurulundan izin alınmıştır (60116787-020/52623).

\section{Bulgular;}

$360^{\circ} \mathrm{d}$ ile altı uzmanlı öğrencisi değerlendirilmiştir. Toplamda 205 form doldurulmuştur. Veri toplama 3 hafta içinde gerçekleştirilmiştir. Elde edilen nicel veriler SPSS programında değerlendirilmiştir. Nitel verileri iki araştırmacı önce birbirlerinden bağımsız, sonra birlikte okuyarak, ortak başlıklar altında toplanmıştır (Tablo 2).

Veri toplama sürecinde en k1demsiz uzmanlık öğrencisi henüz ilk üç ayını doldurmadığı için çok daha kısıtlı sayıda nicel ve nitel veri toplanmıştır. $\mathrm{Bu}$ nedenle nicel istatistik değerlendirmeler 5 uzmanlık öğrencisine ait veriler üzerinden yapılmıştır. İstatistiksel olarak elde edilen verilerden güvenirlik için Cronbach alfa katsayısı hesaplanmıştır. Bu değer on altı maddeden oluşan $\mathrm{P}$ alt anketi için 0.91 , on maddeden oluşan İB alt anketi için 0.68 , beş maddeden oluşan $\mathrm{HB}$ alt anketi için 0.78 ve üç maddeden oluşan STU alt anketi için 0.95 olarak bulunmuştur. Bu Cronbach alfa değerleri sonucu da, profesyonellik ve sistem temelli uygulama için mükemmel, hasta bakımı için iyi ve iletişim içinse kabul edilebilir seviyede iç tutarlığa ulaşıldığ1 görülmüştür. Bu sonuçlar anketin güvenilir olduğunu göstermektedir.

Anketlerden alınan puanlarda uzmanlık öğrencilerinin kıdemleriyle bir artış olduğu görülmüştür (Tablo 3 ) İstatistik olarak da artan kıdem yılı ile toplanan puanlar arasında pozitif yönde istatistiksel olarak anlamlı kuvvetli korelasyon saptanmıştır. İstatistik değerler profesyonellik için $\mathrm{p}=0.001 ; \mathrm{r}=0.991$, iletişim becerileri için $\mathrm{p}=0.005 ; \mathrm{r}=0.974$, hasta bakımı için $\mathrm{p}=0.006 ; \mathrm{r}=0.971$, sistem temelli uygulama içinse $\mathrm{p}=0.005 ; \mathrm{r}=0.975$ ve genel değerlendirme içinse $\mathrm{p}=0.001 ; \mathrm{r}=0.99^{\prime}$ dir.

Tüm değerlendiriciler uygulamayı pozitif karşılayıp, anketleri gönüllü olarak doldurmuşlardır. Bir değerlendirici grubun 
tüm öğrencilere tam puan verdiği görülmüştür. Diğer yandan veri toplama süreci tamamen bire bir araştırmacılar tarafindan ve basılı anket formları ile yapıldığı için çok zaman almıştır. Değerlendirme sürecinde farklı gruplara ait, çok sayıda veri toplanmış olması değerlendirmenin güvenirliğini artırırken, değerlendirme sürecini zorlaştırmıştır.

\section{TARTIŞMA}

Veri toplama aracı; Veri toplamada kullanılan anketler değerlendirilen her başlık için çok sayıda madde içermektedir. Bu da daha spesifik bilgi toplanmasına yardım ederken, gerek veri toplama gerekse de sonuçları değerlendirme işlemlerini zorlaştırmaktadır. Alan yazında daha genel ve az sayıda sorudan oluşturulmuş anket örneklerine de rastlanmaktadır $(7,8)$. $\mathrm{Bu}$ tür standart bir anketin kullanılması her değerlendirici grup için uygun olmayacaktır $(7,8)$. Her değerlendirici grup için anketlerin modifiye edilmesi gerekse bile, bizim yaptığımız uygulamada kullanılan anketler daha spesifik sonuçlara ulaştırmaktadır. Kullandığımız anketlerin önceden geçerlik ve güvenirliği gösterilmiştir (5). Bu çalışma sonuçlarında da her alt başlık için Cronbach alfa hesaplanarak bu araştırma verilerine yönelik güvenirlik incelenmiştir. Sonuçlardan da kullanılan anketlerin güvenilir olduğu görülmüştür.

\section{Değerlendirici}

seçimi;

$360^{\circ}$ d'de değerlendiriciler uzmanlık öğrencisinin çalışma ortamında yer alan tüm gruplardan olursa, değerlendirme sonuçları da o oranda geçerli ve güvenilir olacaktır (4). Bu araştırmada KBB uzmanlık öğrencilerinin birlikte çalıştıkları veya çalışma sürecinde etkileşimde bulundukları tüm gruplar çalışmaya dahil edilmeye çalışılmıştır. KBB uzmanlık öğrencileri için birlikte çalışılan odyometristler ve odyologlar $360^{\circ} \mathrm{d}$ için uygun bir değerlendirici grubudur. Bu çalışmaya da değerlendirici olarak katılmışlardır. Sonradan fark edilmiştir ki cerrahi branşlar için birlikte çalıştıkları bir grup olan anestezistler de değerlendirici olabilirler. Cerrahi branşlar için uygulanacak $360^{\circ} \mathrm{d}$ anestezi ekibi de değerlendirici olarak yer almalıdır. Bu çalışmada tıp fakültesi öğrencilerden de geri bildirim alınmıştır. Mezuniyet öncesi eğitimin yer aldığı kurumlarda tıp fakültesi öğrencileri, KBB uzmanlık öğrencileriyle özelikle polikliniklerde sıklıkla birlikte çalışmaktadırlar. Araştırmacılar olarak KBB uzmanlık öğrencileriyle zaman geçiren öğrencilerin geri bildirimlerinin önemli bir veri kaynağ1 olduğunu düşünmekteyiz. Mümkün olan eğitim kliniklerinde yapılacak $360^{\circ}$ d'lerde tıp fakültesi öğrencilerinin de değerlendirici olarak alınmasını öneririz.

\section{Değerlendiricilerin güvenirliği; $360^{\circ} \mathrm{d}$ 'nin} başarısı, değerlendiricilerin objektif puanlamasına, sonuçların uygun bir geri bildirim sağlayacak şekilde verilmesine ve uzmanlık öğrencilerinin de geri bildirim alabilme becerilerine bağlıdır. Bu araştırmada değerlendiren gruplardan birisinin anketlerdeki tüm maddelere tüm uzmanlık öğrencileri için tam puan verdiği dikkat çekicidir. Bunun geribildirim kültürünün eksik olduğunun bir göstergesi olabileceği, sonuçları gören değerlendiricilerin tekrarlayan $360^{\circ} \mathrm{d}$ 'lerde bu tutumlarını değiştirecekleri düşünülmüştür.

\section{Veri toplamadaki ve değerlendirmedeki} zorluklar; Araştırmacılar bu çalışmada veri toplama sürecine çok zaman ayırmışlardır. Bu durum ilk uygulama yapılmasının getirdiği zorluklar olabilir. Gelecekteki rutin uygulamalar için verilerin çevrim içi araçlarla toplanması bu sürenin k1saltılması önerilir. Yine de çevrim içi araçları kullanamayacak olan, hastalar gibi 
gruplarda yüz yüze veri toplamak gerekebilir. Özellikle çok sayıda uzmanlık öğrencisinin eğitim aldığı kalabalık klinikler başta olmak üzere, çevrim içi yöntemler kullanılsa bile $360^{\circ} \mathrm{d}$ için gerek veri toplama, gerekse de raporlama sürecinin kolay olmayacağı aşikardır. $\mathrm{Bu}$ tür kaygılar alan yazında da bildirilmiştir $(5,6)$.

Bir diğer önemli nokta da toplanan verilerden elde edilen sonuçların değerlendirilmesidir. Her öğrenci için toplanan verilerin bir arada değerlendirilip öğrenci için kuvvetli ve geliştirilebilir alanların bildirilmesi de yoğun iş gücü ve deneyim gerektirmektedir (9). Eğer $360^{\circ} \mathrm{d}$ uzmanlık eğitiminde rutin yapılacaksa verilerin değerlendirilmesi ve öğrenci için anlamlı bir geri bildirim oluşturma veya saptanan sorunların çözülmesi konusunda mutlaka profesyonel danışmana ihtiyaç olacaktır. $\mathrm{Bu}$ danışman eğitim almış rehber uzmanlar veya psikologlar olabilir. Örneğin iletişim beceriler gibi alanlardaki sorunlar içinse yapılandırılmış kurslar çözüm olabilir.

Tepkiler; $360^{\circ} \mathrm{d}$ değerlendirici gruplar ve eğiticiler tarafından ilgiyle karşılanmıştır. Yazılı geri bildirimlerden uzmanlık öğrencilerinin de bu değerlendirmeyi pozitif karşıladıkları anlaşılmaktadır (Tablo 2). Alan yazındaki diğer örneklerde de $360^{\circ}$ d'nin gerek öğrenciler, gerekse de değerlendiriciler tarafindan kabul gördüğü yönündedir $(5-8,10,11)$

Kıdem ve alınan puan ilişkisi; Her uzmanlık öğrencisinin alt anketlerden aldığı puan ortalamaları ise Tablo 3'de görülmektedir. Dikkat çekici nokta kıdem arttıkça alınan puanların arttığıdır. Benzer sonuçlar alan yazında da bildirilmiştir (12). Bu sonuçlar uzmanlık öğrencilerinin değerlendirilen alanlarda yapılandırılmış bir eğitim programı olmasa bile kıdemlilerini ve öğretim üyelerini izleyerek, ya da eğitim sürecindeki deneyimlerine bağlı olarak kendilerini geliştirdikleri yönünde yorumlanabilir. $\mathrm{Bu}$ sonuç yine de bu alanlar için eğitsel kaynak oluşturulması veya yapılandırılmış eğitim programı yapılması gerekliliğini ortadan kaldırmayacaktır.

$360^{\circ} \mathbf{d}^{\prime}$ nin davranışa etkileri; Alan yazındaki $360^{\circ}$ değerlendirme ile ilgili en önemli sorulardan birisi de elde edilen geri bildirimlerin davranış değişikliğine yol açıp açmayacağıdır $(13,14)$. Araştırmaya katılan uzmanlık öğrencilerinden bir tanesi bu konuda, $360^{\circ} \mathrm{d}$ ile değerlendirilenlerin kişisel özelik olduğunu ve geri bildirimlerin davranış değişikliğine yol açmayacağını söylemiştir. Kalan uzmanlık öğrencilerinden birisi kısmen diye cevaplarken, kalanı ise evet demiştir. Öğretim üyeleri ise sonuçların uzmanlık öğrencilerine bir otorite tarafından bildirildiği için davranış değişikliğine yol açacağını düşünmüşlerdir. Alan yazında ilk $360^{\circ} \mathrm{d}$ sonrasinda 6 . ayın sonunda $\% 32$ oranında davranış değişikliği rapor edilmiştir (15).

\section{Negatif sonuçların bildirilmesindeki}

zorluklar; Süreçte araştırmacıların karşılaştığ1 en önemli zorluklardan birisi de özelikle düşük puan alınan noktalarda ve negatif geri bildirimlere uzmanlık öğrencilerinin nasıl tepki vereceklerinin bilinmemesidir. $\mathrm{Bu}$ araştırmada geri bildirim aşamasında bazı sorunlar yaşanmış ve bazı sonuçlar geribildirimden daha çok kişisel algılanmıştır. Bunun nedeni $360^{\circ} \mathrm{d}$ 'nin ilk kez uygulanıyor olması ve geribildirim kültürünün ülkemizde henüz yerleşmemiş olması olabilir. Alan yazında tarafların $360^{\circ}$ d'yi kabul etmelerine ve ilgiyle karşılamalarına rağmen geri bildirimlerin karşılıklı olması gibi önerileri olmuştur (14).

İletişim ve profesyonellik gibi alanlarda sorunlar saptandığında rehberlik yapacak 
danışman uzmanlara veya eğitim programlarına ihtiyaç olacaktır. $360^{\circ} \mathrm{d}$ rutin uygulanacaksa, uzmanlık eğitimi verilen hastanelerde konuyla ilgili eğiticilerin eğitimi gerekebilir (16). Aksi takdirde sadece sonuçların bildirilmesi işe yaramayabilir. Alan yazında ABD'de KBB uzmanlık öğrencileri için iletişim becerileri ve profesyonellik gibi alanlarda sorunlu uzmanlık öğrencilerinin genelde ilk geri bildirimden sonra sorunlu davranışı düzelttiği, düzelmeyen durumlarda ise konu ile ilgili düzenli geri bildirim toplantıları yapıldığ 1 bildirilmiştir (17). $360^{\circ}$ d'de uzun dönemde izlem de gereklidir. $\mathrm{Bu}$ da rutin uygulama için planlama gerektiren bir başka noktadır.

Eğitim İhtiyacı; Sonuçlar uzmanlık öğrencilerine bireysel olarak bildirildikten sonraki toplantıda uzmanlık öğrencileri değerlendirilen alanlarda eğitim ihtiyacı hissetmişlerdir. Ülkemizde iletişim becerileri konusunda eğitimlere ait raporlara alan yazında az da olsa rastlanmaktadır (18). KBB hastalıklarında hasta hekim iletişim başlıklı bir bölüm 2013 y1lında basılan Koç editörlüğündeki KBB uzmanlık eğitim kitabında yer almıştır (19). $\mathrm{Bu}$ hasta hekim iletişim bölümü ülkemizdeki tüm uzmanlık alanlarındaki ilk ve tek örnektir. Diğer yandan KBB yeterlik sınavındaki en düşük puan alınan basamaklardan birisinin de iletişim becerileri basamağı olduğu bildirilmiştir (20). Değerlendirilen alanlardan profesyonalizm de ülkemiz için yeni tartışmaya açılan bir alandır $(21,22)$. Bu konularda her KBB uzmanlık öğrencisinin kolayca ulaşabileceği eğitsel kaynaklara ve uygulamalı kurslara ihtiyaç vardir.

Sınırlılıklar; $\mathrm{Bu}$ araştırma nispeten uzmanlık öğrenci sayısının az olduğu bir grupta yapılmıştır. Çok uzmanlık öğrencisi olan eğitim kliniklerinde daha farklı zorluklarla karşılaşılabilinir. Bir diğer sınırlılık ise uygulamanın kesitsel olmasıdır. Uzmanlık öğrencileri de geri bildirimlerinde bu konuya dikkat çekmişler ve değerlendirmenin belli aralarla düzenli olarak yapılmasını önermişlerdir (Tablo 2). Gerçekten de $360^{\circ} \mathrm{d}$ yöntemi önerildiği gibi her yıl tekrarlanırsa uzmanlık öğrencilerinin değerlendirilen maddelerdeki değişimleri ve kendi gelişimlerini görmeleri sağlanabilir. $360^{\circ} \mathrm{d}$ ve geri bildirim kültürü de bu şekilde yaygınlaşacaktır.

Yeterlik temelli uzmanlık eğitiminde tüm yeterlik alanlarında öğrenci gelişiminin gösterilmesi gerekmektedir. $\mathrm{Bu}$ alanda sıklıkla iş başında ölçme değerlendirme araçları kullanılmaktadır $(3,23,24)$. Örneğin "işlem becerilerinin doğrudan gözlemi" ya da "cerrahi beceri cetveli" uygulamaları KBB uzmanlık alanına spesifik olduğu için daha kolay kullanılabilecek araçlardır $(23,24) . \mathrm{Bu}$ araştırmadan da görülmektedir ki $360^{\circ} \mathrm{d}$ iş başında ölçme değerlendirme araçları arasında uygulaması en zor ölçme değerlendirme aracıdır. Alan yazında da $360^{\circ} \mathrm{d}$ yoğun iş yükü gerektirdiğine yönelik düşünceler dile getirilmiştir. $(5,25) .360^{\circ} \mathrm{d}$ yeterlik temelli uzmanlık eğitiminin en önemli araçlarından birisi olarak muhtemel ülkemizdeki yeterlik temelli KBB uzmanlık eğitimi sürecinde de rutin uygulamaya girecektir. $\mathrm{Bu}$ ve benzeri bağımsız araştırma sonuçları rutin uygulamaya geçişte yol gösterici olacaktır.

\section{SONUÇ}

$360^{\circ} \mathrm{d}$ uzmanlık eğitiminde rutin uygulama için bu araştırmadan çıkan sonuçlar şunlardır.

1. Spesifik bilgi edinilmesi için bu araştırmada kullanılan örneklerde olduğu gibi amaca yönelik anketlerin kullanılması 
2. Uzmanlık öğrencisinin çalışma alanında yer alan tüm çalş̧anların (KBB için odyologlar, cerrahlar için anestezi ekibi üyeleri, tıp fakültesi öğrencileri gibi) değerlendirici olarak alınması,

3. Veri toplama süresinin kısaltılması için çevrim içi anketler kullanılması,

4. Özellikle iyileştirilmesi gereken noktaların uzmanlık öğrencilerine bildirilmesinde olası tepkilere hazırlıklı olunması,

5. İyileştirilmesi gereken alanlar için de eğitim veya danışmanlık olanaklarının hazırlanması,

6. Tekrarlayan ölçümlerle uzmanlık öğrencilerinin gelişimlerinin izlenmesi önerilir.

Finansal Destek: Yazarlar bu çalı̧̧ma için finansal destek almadıklarını beyan etmişlerdir.

\section{Kaynaklar;}

1. Tipta Uzmanlık Kurulu, KBB hastalıkları çekirdek programı

http://www.tuk.saglik.gov.tr/muf2.1/kulak_ burun_bogaz_hastaliklari/kulak_burun_bogaz hastaliklari_mufredat_v.2.1.pdf(Aralık 2018'de ulaşıldı)

2. Türk Kulak Burun Boğaz Ve BaşBoyun Cerrahisi Uzmanlık Eğitimi Karnesi Kullanım Rehberi http:/www.kbb.org.tr/ TKBBBBCDData/Document/3092016153854rehber2016.pdf (Nisan 2019'da ulaşıld1)

3. Türk Kulak Burun Boğaz Ve BaşBoyun Cerrahisi Uzmanlık Eğitimi Karnesi http://www.kbb.org.tr/tr/files/download/ p1c4758uap85t1ata115o1js02ug4.pdf (Nisan 2019'da ulaşıldı)
4. Amin Z, Seng CY, Eng KH. In: Tip eğitiminde ölçme değerlendirme için pratik rehber. Çeviri editörleri; Kara CO, Sarığlu-Büke A. İstanbul: İstabul Tip Kitabevi, 2011 p.71-74

5. Oktay C, Senol Y, Rinnert S, Cete Y. Utility of 360-degree assessment of residents in a Turkish academic emergency medicine residency program. Turk J Emerg Med. 2016;17:12-15

6. Senol Y, Dicle O, Durak HI. Evaluation of Dermatology Residents Using the Multisource (360-Degree) Assessment Method. Kuwait Medical Journal 2009;41:205-209

7. Tariq M, Boulet J, Motiwala A, Sajjad N, Ali SK. A 360-degree evaluation of the communication and interpersonal skills of medicine resident physicians in Pakistan. Educ Health (Abingdon). 2014;27:269-76

8. Sadeghi T, Loripoor M. Usefulness of 360 degree evaluation in evaluating nursing students in Iran. Korean J Med Educ. 2016;28:195-200.

9. Sargeant J, McNaughton E, Mercer S, Murphy D, Sullivan P, Bruce DA. Providing feedback: exploring a model (emotion, content, outcomes) for facilitating multisource feedback. Med Teach. 2011;33:744-9

10. Zhao Y, Zhang X, Chang Q, Sun B. Psychometric characteristics of the $360^{\circ}$ feedback scales in professionalism and interpersonal and communication skills assessment of surgery residents in China. J Surg Educ. 2013;70:628-35.

11. Alofs L, Huiskes J, Heineman MJ, Buis C, Horsman M, van der Plank L, Ten Cate O. User reception of a simple online multisource feedback tool for residents. Perspect Med Educ. 2015;4:57-65 
12. Jani H, Narmawala W, Ganjawale J. Evaluation of Competencies Related to Personal Attributes of Resident Doctors by 360 Degree. J Clin Diagn Res. 2017;11:JC09-JC11.

\section{Ferguson J, Wakeling J, Bowie P. Factors} influencing the effectiveness of multisource feedback in improving the professional practice of medical doctors: a systematic review. BMC Med Educ. 2014;11;14:76.

14. Yama BA, Hodgins M, Boydell K, Schwartz SB. A qualitative exploration: questioning multisource feedback in residency education. BMC Med Educ. 2018; 24;18:170.

15. Nurudeen SM, Kwakye G, Berry WR, Chaikof EL, Lillemoe KD, Millham F, Rubin M, Schwaitzberg S, Shamberger RC, Zinner MJ, Sato L, Lipsitz S, Gawande AA, Haynes AB Can 360-Degree Reviews Help Surgeons? Evaluation of Multisource Feedback for Surgeons in a Multi-Institutional Quality Improvement Project. J Am Coll Surg. 2015;221:837-44.

16. Faucett EA, McCrary HC, Barry JY, Saleh AA, Erman AB, Ishman SL. High-Quality Feedback Regarding Professionalism and Communication Skills in Otolaryngology Resident Education. Otolaryngol Head Neck Surg. 2018;158:36-42.

17. Bhatti NI, Ahmed A, Stewart MG, Miller RH, Choi SS. Remediation of problematic residents--A national survey. Laryngoscope. 2016;126:834-8.

18. Karabilgin ÖS. Ege Üniversitesi T1p Fakültesi İç hastalıkları anabilim dalı asistan eğitimi için iletişim becerileri program tasarımı ve uygulaması. Tıp Eğitimi Dünyası 2007;25:25-34.
19. Özdemir S, Kara CO. Kulak burun boğaz hastalıklarında hasta-hekim iletişimi. in Kulak Burun Boğaz Hastalıkları ve Baş Boyun Cerrahisi Editör: Can Koç. Ankara: Güneş Tıp Kitabevleri, 2013 p.3-11

20. Kara CO, Daloğlu M. Kulak burun boğaz uzmanlık eğitim programları standartizasyonu: Öğrenciler ve eğiticiler konuşuyor Tip Eğitimi Dünyası 2018; 51:72-75

21. Faucett EA, Barry JY, McCrary HC, Saleh AA, Erman AB, Ishman SL. Otolaryngology Resident Education and the Accreditation Council for Graduate Medical Education Core Competencies: A Systematic Review. JAMA Otolaryngol Head Neck Surg. 2018;144:360370

22. Sarığlu Büke A, Karabilgin Öztürkçü ÖS, Yılmaz Y, Sayek İ. Core Professionalism Education in Surgery: A Systematic Review. Balkan Med J. 2018;35:167-173.

23. Kara CO, Mengi E, Tümkaya F, Topuz B, Ardıç FN. Direct Observation of Procedural Skills in Otorhinolaryngology Training. Turk Arch Otorhinolaryngol 2018; 56: 7-14

24. Kara CO, Mengi E, Tümkaya F, Ardıç FN, Şenol H. Adaptation of "Objective Structured Assessment of Technical Skills" for Adenotonsillectomy into Turkish: A Validity and Reliability Study. Turk Arch Otorhinolaryngol 2019; 57: 7-13

25. Weigelt JA, Brasel KJ, Bragg D, Simpson D. The 360-degree evaluation: increased work with little return? Curr Surg. 2004;61:616-26 
Tablo 1: Hangi anketlerin hangi gruplarda kullanıldığı ve değerlendiricilerin görev yerleri ve sayılan görülmektedir

\begin{tabular}{|l|l|l|}
\hline Değerlendiriciler & $\begin{array}{l}\text { Değerlendiricilerin sayısı ve } \\
\text { calıștığı yerler }\end{array}$ & Anketler \\
\hline $\begin{array}{l}\text { Eğiticiler } \\
\text { (Öğretim üyeleri) }\end{array}$ & 5 & $\mathrm{p}, \mathrm{i}, \mathrm{stu}$ \\
\hline Hemşireler & $\begin{array}{l}\text { 6 (poliklinik 1, yataklı servis 5, } \\
\text { ameliyathane 2) }\end{array}$ & $\mathrm{p}, \mathrm{i}, \mathrm{hb}$, stu \\
\hline Sekreterler & 4 (poliklinik 2, yataklı servis 2) & $\mathrm{p}, \mathrm{i}$ \\
\hline Personel & $\begin{array}{l}5 \text { (poliklinik 1, yataklı servis 2, } \\
\text { ameliyathane 2) }\end{array}$ & $\mathrm{p}, \mathrm{i}$ \\
\hline Odyometrisler & 4 & $\mathrm{i}$ \\
\hline Akran değerlendirme & 6 & $\mathrm{p}, \mathrm{i}$ \\
\hline Öz değerlendirme & 6 & $\mathrm{i}$, hb, stu \\
\hline Hasta ve yakınları & 4 & Özel Hazılamıs Anket \\
\hline Öğrenciler & 6 & \\
\hline
\end{tabular}

p: Profesyonellik, i: Iletişim Becerisi, hb: Hasta Bakımı, stu: Sistem temelli uygulama 
Tablo 2: Uzmanlık öğrencileri ve ögretim üyelerinin $360^{\circ}$ değerlendirme konusundaki geri bildirim sonuçları özetlenmiştir. Sorular yazılı istenen geri bildirim formundaki sorulardır.

Geri bildirim toplama süreci ve şekli konusunda önerileriniz var mıdır? Eksiklerimizi görmemiz açısından faydalı olmuștur. Bu alanlarda kendimizi geliștirebiliriz. Pozitif geribildirimler özgüvenimizi artırırken, negatif olanlarda eksikliklerimizi fark etmemizi sağlamıștır.

Geri bildirimler gercekci midir?

Uzmanlık öğrencilerinden bir kiși kısmen diye cevaplarken, diğerleri evet diye cevaplamıștır. Öğretim üyeleri evet diye cevaplamıștır

Bu geri bildirimlere sizde katılıyor musunuz?

Hem uzmanlık öğrencileri, hem de öğretim üyeleri evet diye cevaplamışlardır.

Adil bir uvgulama midir?

Uzmanlık öğrencilerinden bir kiși kısmen diye cevaplarken, diğerleri evet diye cevaplamıștır. Öğretim üyeleri evet diye cevaplamıștır.

Sizce bu tür geri bildirimler uzmanlık öğrencisinin davranıșlarında değişiklik vapar $\underline{\mathrm{mi}}$ ?

Uzmanlık öğrencilerinden bir kişi 360 ile yapılan değerlendirmenin kişisel özelikler olduğunu ve değişmeyeceğini söylemiştir. Bir öğrenci kısmen diye cevaplarken, diğerleri evet diye cevaplamıştır.

Öğretim üyeleri ise değerlendirme sürecinin eğiticiler tarafindan organize edilmesi ve ögretim üyelerinden oluşan bir grup tarafindan uzmanlık öğrencilerine yüz yüze yapılan bir toplantıda, sözel olarak da bildirildiẹi için davranış değișikliğine yol açacaĕını bildirdiler.

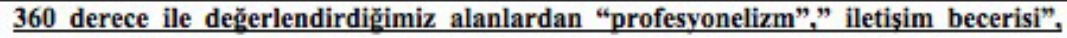
"sistem temelli

Uygulama", "hasta bakımı" gibi konularda uzmanlık eğitimi sürecinde yapılandırılmıs ę̌itimler vapılmasını ister misiniz?

Uzmanlık öğrencileri değerlendirildikleri tüm başlıklarda eğitim olanakları sunulmasını istediler. Ama nasıl, ne zaman ve ne kadar süre ile yapılması konusunda kararsız kaldılar.

Bu tür 360 derece değerlendirme ülkemiz uzmanhk eğitimi için uygun mudur?

Uzmanlık öğrencilerinden bir kiși kısmen diye cevaplarken, diğerleri evet diye cevaplamıștır.

Öğretim üyeleri evet diye cevaplamıștır.

$\underline{360 \text { derece değerlendirme ile ilgili eklemek istedikleriniz nelerdir? }}$

Daha genis bir zamana yayilmalı ve daha uzun sürede toplanmalıdır. 
Tablo 3. KBB Uzmanlık öğrencilerinin $360^{\circ}$ değerlendirmede anket alt başlıklarından aldıkları puanların kıdem yıllarına göre sıralanması

\begin{tabular}{|c|c|l|c|c|c|}
\hline $\begin{array}{l}\text { KIDEM } \\
\text { YILLARI }\end{array}$ & PROFESYONALIZM & $\begin{array}{l}\text { HASTA } \\
\text { BAKIMI: } \\
\text { BECERILER }\end{array}$ & $\begin{array}{l}\text { ÍLETIŞiM } \\
\text { BECERÍSi }\end{array}$ & $\begin{array}{l}\text { SISTEM } \\
\text { TEMELLİ } \\
\text { UYGULAMA }\end{array}$ & GENEL \\
\hline 1 & 3.66 & 3.48 & 3.46 & 2.85 & 2.4 \\
\hline 3 & 4.37 & 3.92 & 4.27 & 3.75 & 3.8 \\
\hline 4 & 4.56 & 4.62 & 4.82 & 4.75 & 4.71 \\
\hline 4 & 4.5 & 4.44 & 4.56 & 4.28 & 4.42 \\
\hline 5 & 4.85 & 4.96 & 4.85 & 5 & 5 \\
\hline
\end{tabular}

Kıdem yılı arttıkça uzmanlık öğrencilerinin dört anketten aldıkları puanlarda istatistiksel olarak artış saptanmıştır.

\section{Ayrintular}

\begin{tabular}{ll}
\hline Birincil Dil & tr \\
\hline Konular & Sağglik Bilimleri ve Hizmeticri \\
\hline Dergi Bölümü & Orjinal Araşturma \\
\hline Yazarlar & $\begin{array}{l}\text { Orcid: 0000-0003-2219-4283 } \\
\text { Yazar: Cüncyt Orhan Kara (Sorumlu Yazar) } \\
\text { Kurum: PAMUKKALE UNIVERSITESI, TIP FAKULTESI } \\
\text { Čllke: Turkey }\end{array}$ \\
\hline
\end{tabular}

Orcid: 0000-0001-8813-2443

Yazar: Erdem Mengi

Kurum: PAMUKKALE ONIVERSITESI, TIP FAKOLTESI

Clike: Turkey 